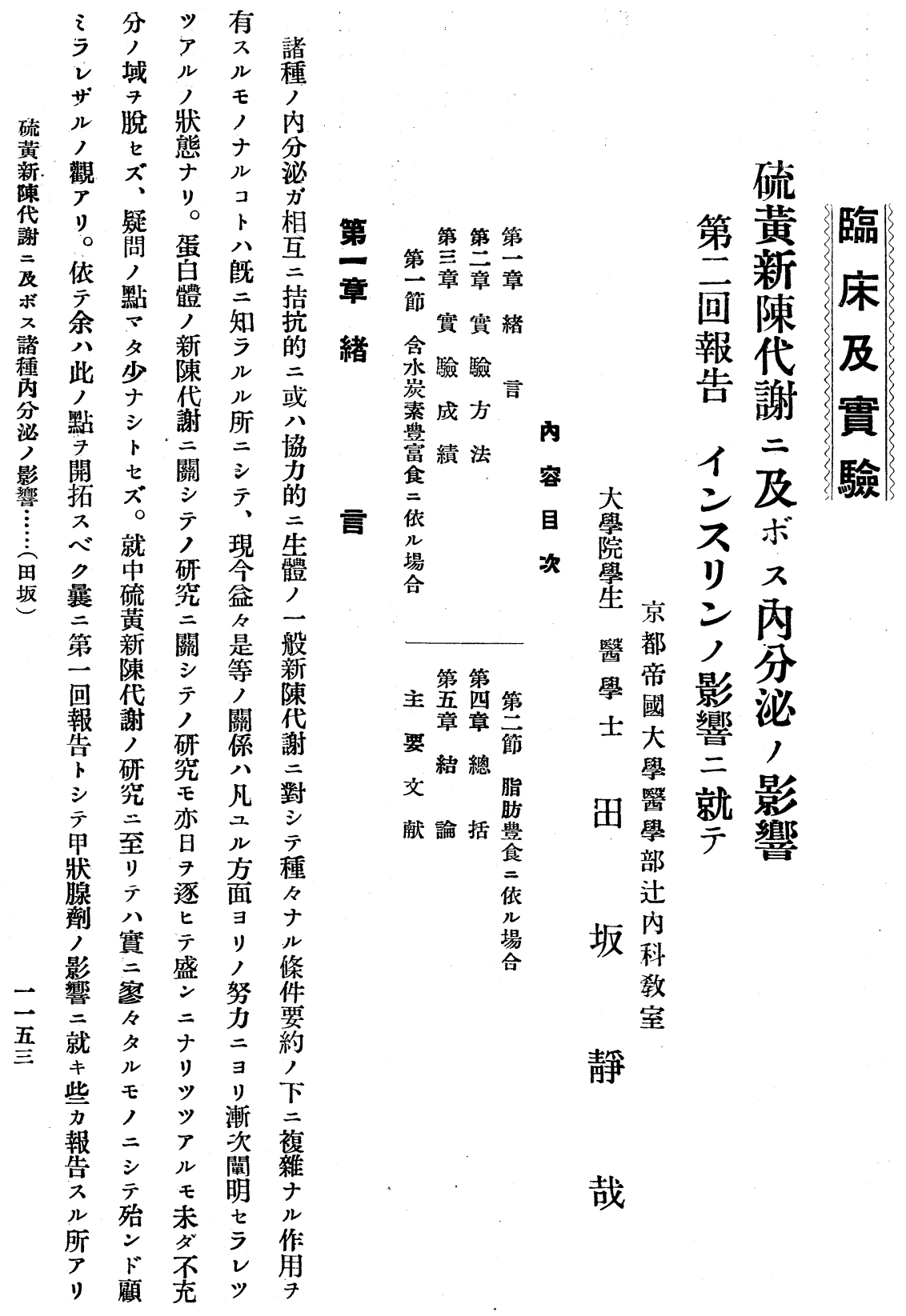



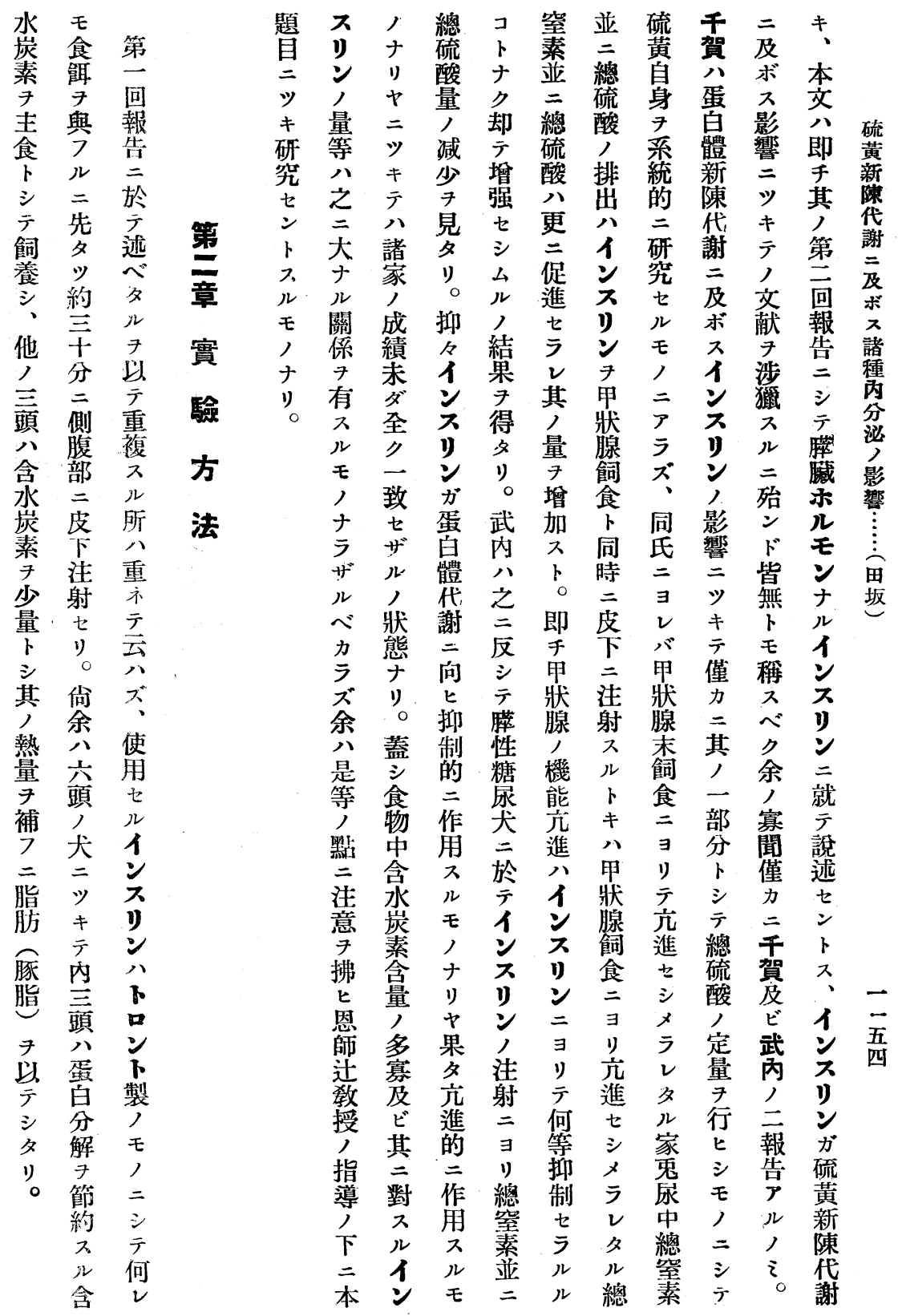


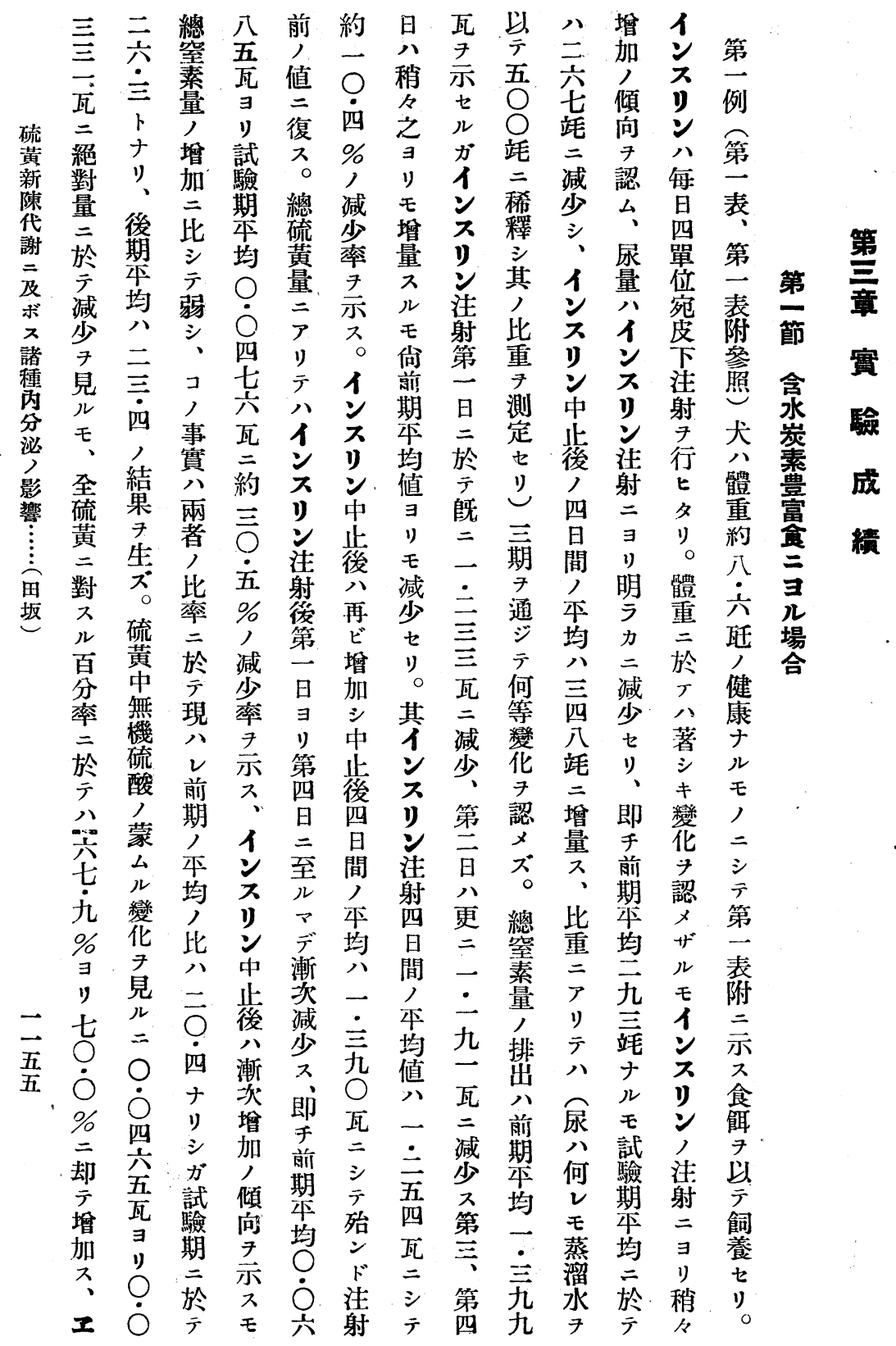




\begin{tabular}{|c|c|c|c|c|c|c|c|c|c|}
\hline$\frac{1}{5}$ & 遄 & 决 & 蓬 & 些 & 邁 & 羏 & & & \\
\hline $\begin{array}{l}\text { 几 } \\
\text { 硫 } \\
\text { 酸 }\end{array}$ & & 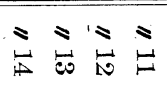 & & $\begin{array}{lll}s & s & s \\
& 0 & \infty\end{array}$ & & 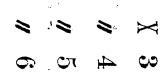 & 工 & 鄂 鹳 & \\
\hline 0 & $\stackrel{\infty}{\infty}$ & 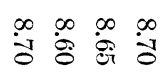 & $\stackrel{\infty}{\infty}$ & 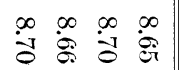 & $\stackrel{\infty}{\infty}$ & 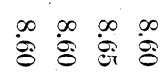 & 醇 & 形跣 & \\
\hline 0 & $\infty_{\infty}^{\infty}$ & 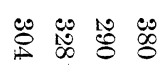 & $\stackrel{N}{G}$ & 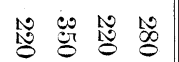 & 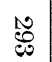 & 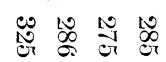 & 命 & 标 & \\
\hline $\overrightarrow{\bar{F}}$ & $=$ & $s=s$ & $=$ & $s=s$ 姆 & $=$ & $\therefore s=$ 票 & 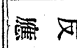 & 对 济 & \\
\hline $\begin{array}{l}\exists \\
y\end{array}$ & ڤ્. & 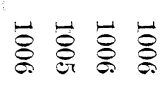 & $\stackrel{8}{8}$ & 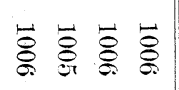 & ڤ. & 芌岕岕总 & 舞 & 눈 & \\
\hline 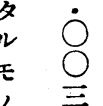 & 范 & 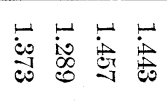 & 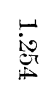 & 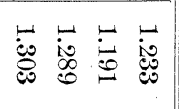 & ت & 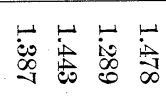 & 昰明 & 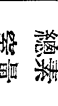 & \\
\hline $\begin{array}{l}\text { 八 } \\
\text { 瓦 } \\
=\end{array}$ & $\stackrel{\circ}{\stackrel{0}{0}}$ & 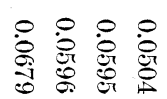 & : & $\begin{array}{l}\dot{0} \\
\dot{0}\end{array}$ & 总 & 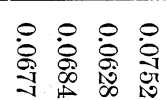 & 昰 & 㽗雉 & \\
\hline $\begin{array}{l}\text { 减 } \\
\text { 少 }\end{array}$ & 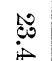 & $\begin{array}{ll}0 \\
0 \\
0\end{array}$ & $\mathscr{c}$ & $\begin{array}{lll}10 & 10 & 0 \\
0 & 0 & 0 \\
0 & 0 & 0\end{array}$ & है & 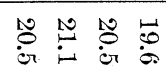 & & $=0$ & 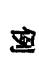 \\
\hline $\begin{array}{l}\text { 其 } \\
\text { 貧 }\end{array}$ & $\begin{array}{l}\stackrel{0}{8} \\
\stackrel{0}{\infty}\end{array}$ & 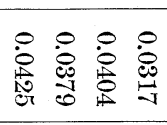 & 总 & 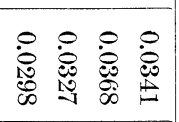 & 总 & 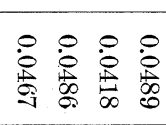 & 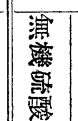 & 䆛 & $\begin{array}{l}1 \\
1\end{array}$ \\
\hline $\begin{array}{l}\text { 率 } \\
\text { 父 } \\
\text { 又 }\end{array}$ & 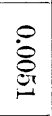 & 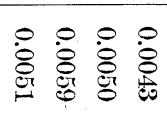 & $\begin{array}{l}\dot{0} \\
\dot{8} \\
\dot{\infty} \\
\infty\end{array}$ & 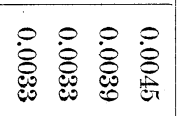 & $\stackrel{8}{\circ}$ & 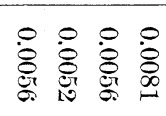 & 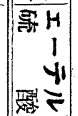 & 影 & 肼 \\
\hline $\begin{array}{l}\text { 八 } \\
\dot{\text { 九 }} \\
\%\end{array}$ & $\begin{array}{l}\stackrel{\circ}{\circ} \\
\stackrel{8}{8}\end{array}$ & 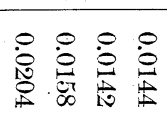 & $\stackrel{8}{\circ}$ & $\begin{array}{l}\dot{0} \\
\dot{0} \\
\dot{0}\end{array}$ & 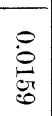 & 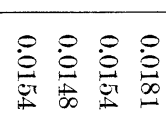 & | & 제 & \\
\hline $\begin{array}{l}\text { り } \\
\text { 七 }\end{array}$ & 趸 & & :ै & & 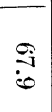 & & 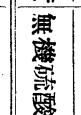 & I & \\
\hline $\begin{array}{l}\text { 九 } \\
\% \\
=\end{array}$ & $\because$ & & -10 & & $\infty$ & & 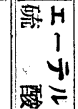 & $\Rightarrow$ & \\
\hline $\begin{array}{l}\text { 柴 } \\
\frac{2}{0} \\
0\end{array}$ & $\stackrel{10}{\circ}$ & & : & & 蛋 & & 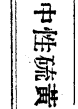 & 量 & \\
\hline $\begin{array}{l}\text { 中 } \\
\text { 性 } \\
\text { 硫 } \\
\text { 黃 }\end{array}$ & & & & $\begin{array}{l}\mu \omega \\
\mu\end{array}$ & & & a* & & \\
\hline
\end{tabular}



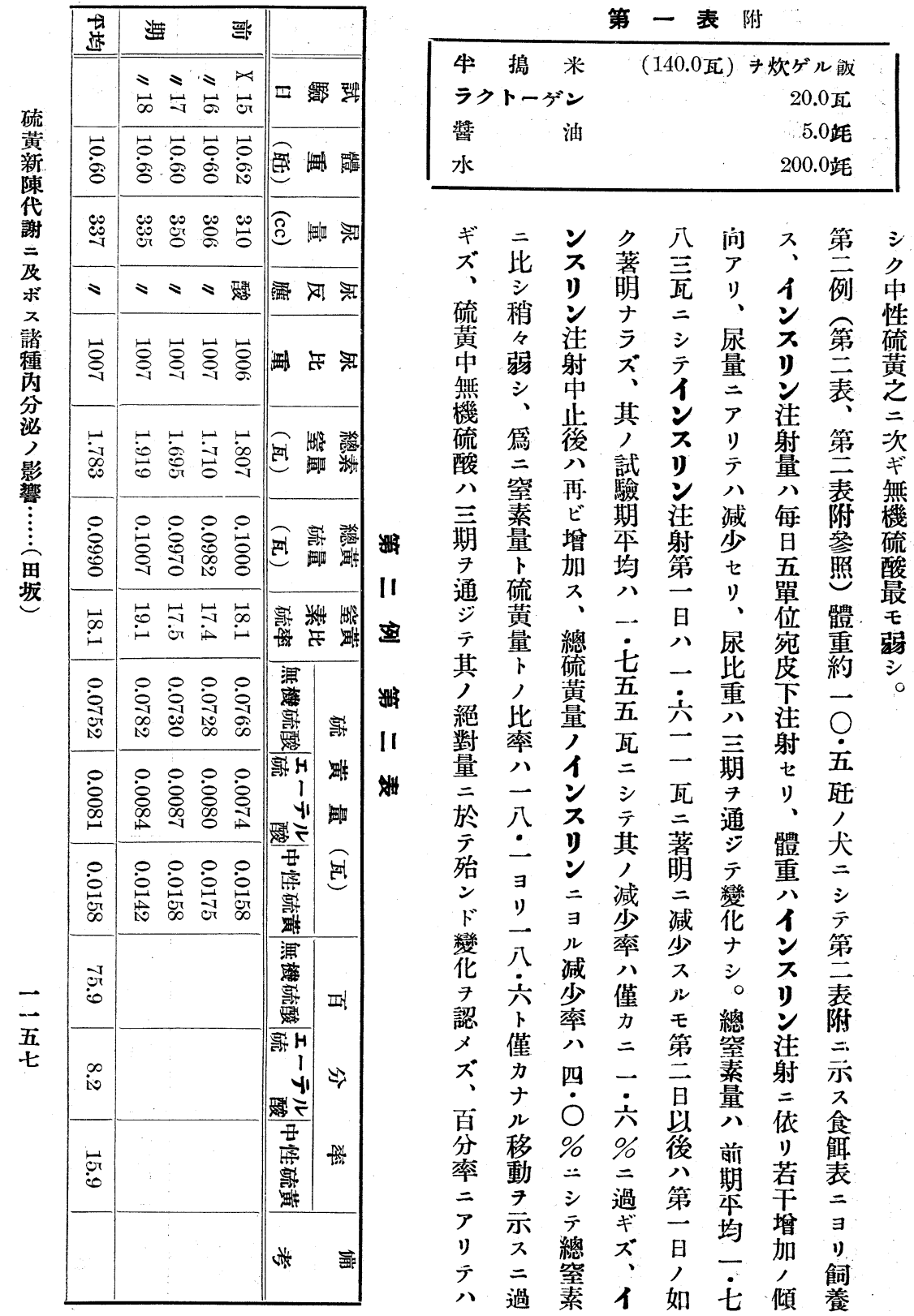

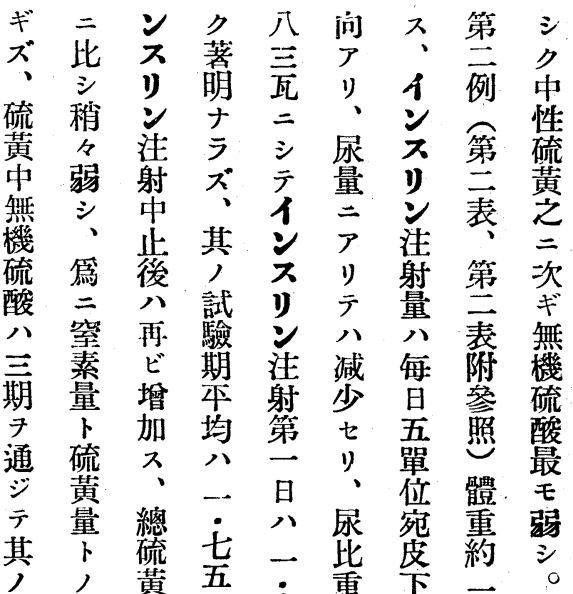

泓比黄畐立重市一

對 率无一互一射五

量

於八元示蔈通體犬

殆立 ソ 其著方體犬

ン

ドリヨ少减华イテ

紫八减率少 ナ

認六省僅 ル

メ僅 八二第窒 注 二

ズ力四一兰素射示

百 $\begin{array}{lllll}\text { ル } & \text { 六 } & \text { 是 } & \text { 量 } & \text { 食 }\end{array}$

分移 $\% \%$ 後前り慨

率動 二 二 等期 若表

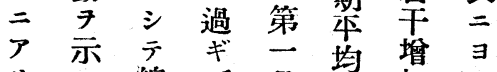

リ 總 $ス$ 日量茄り

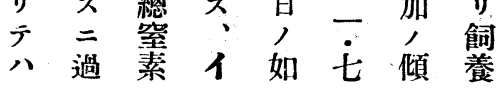




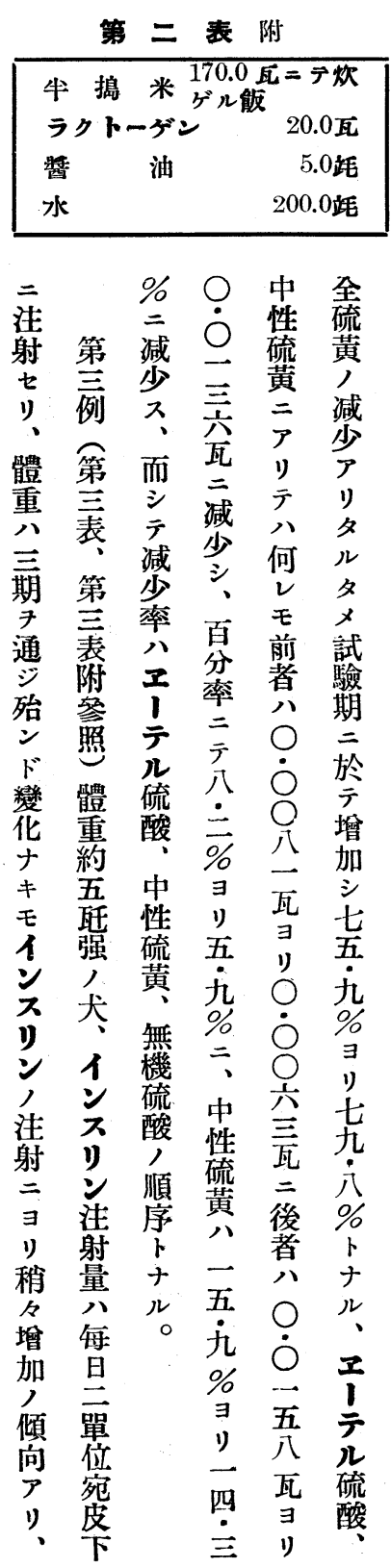

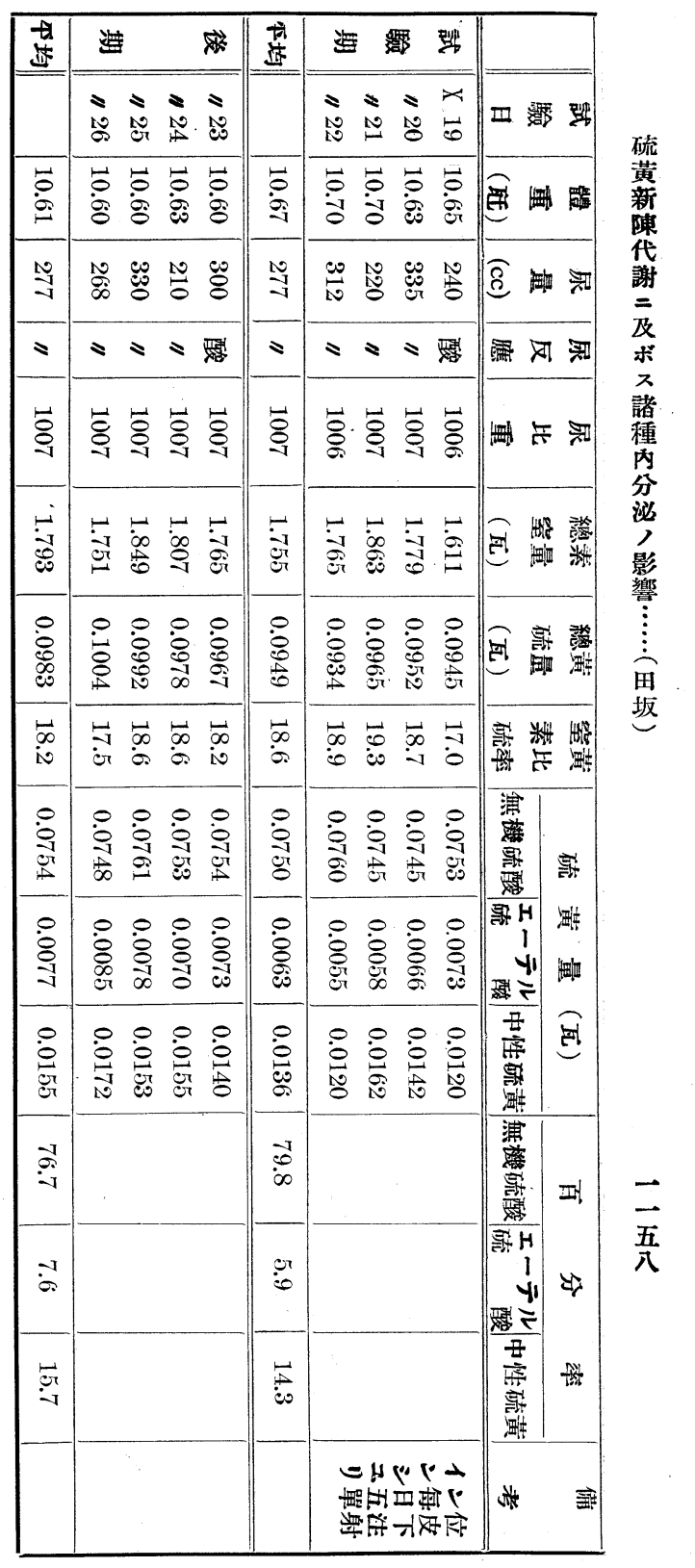




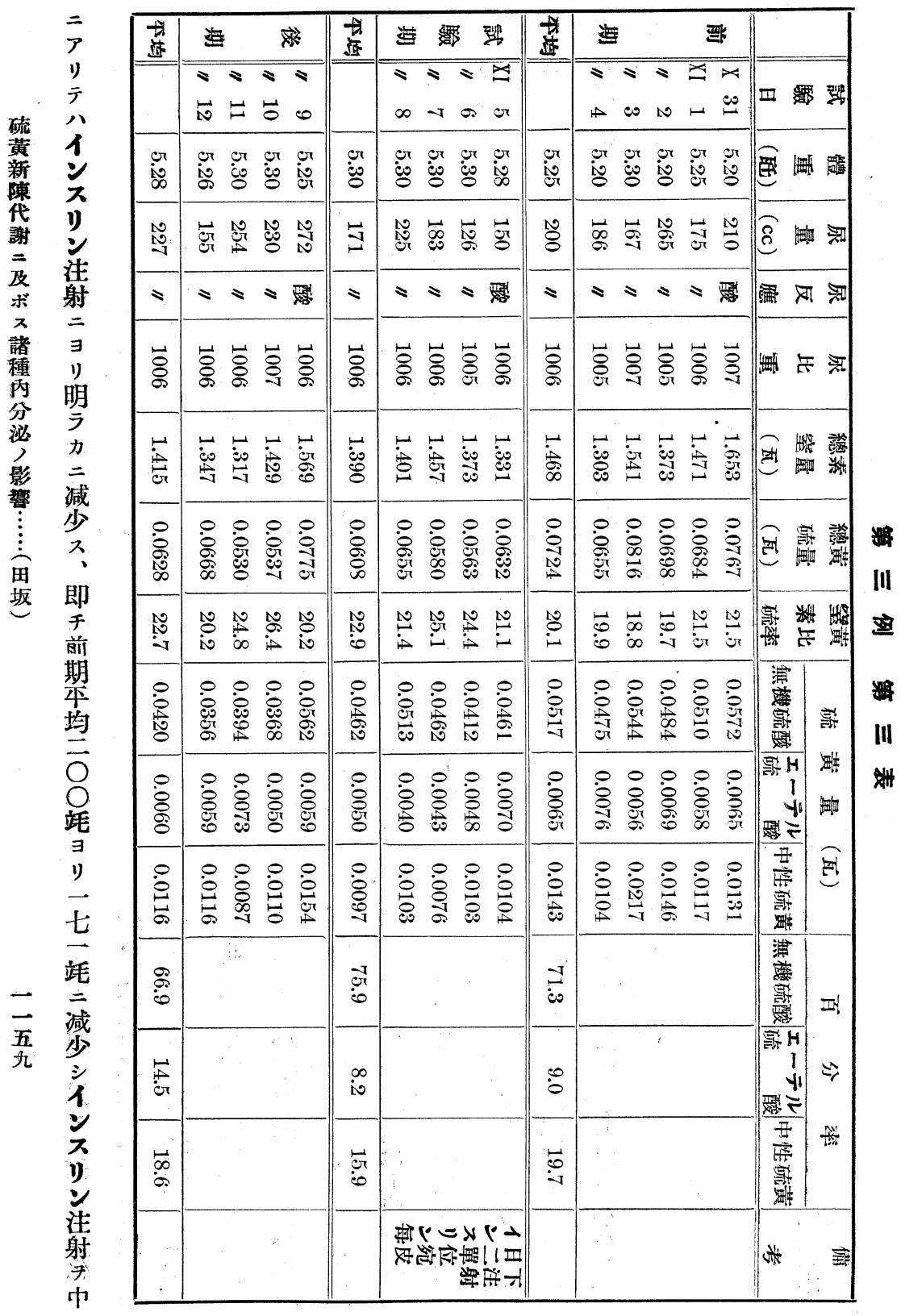




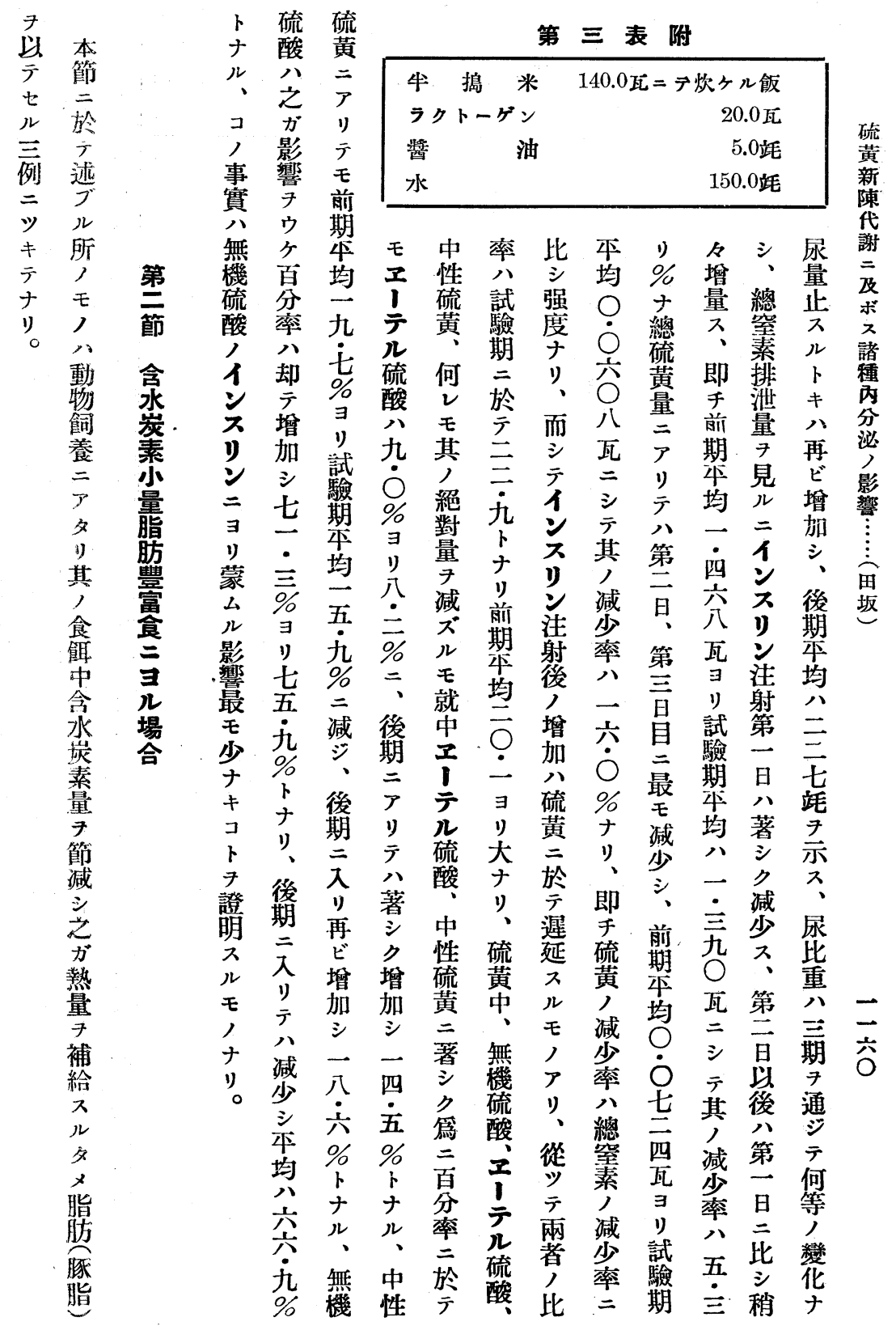




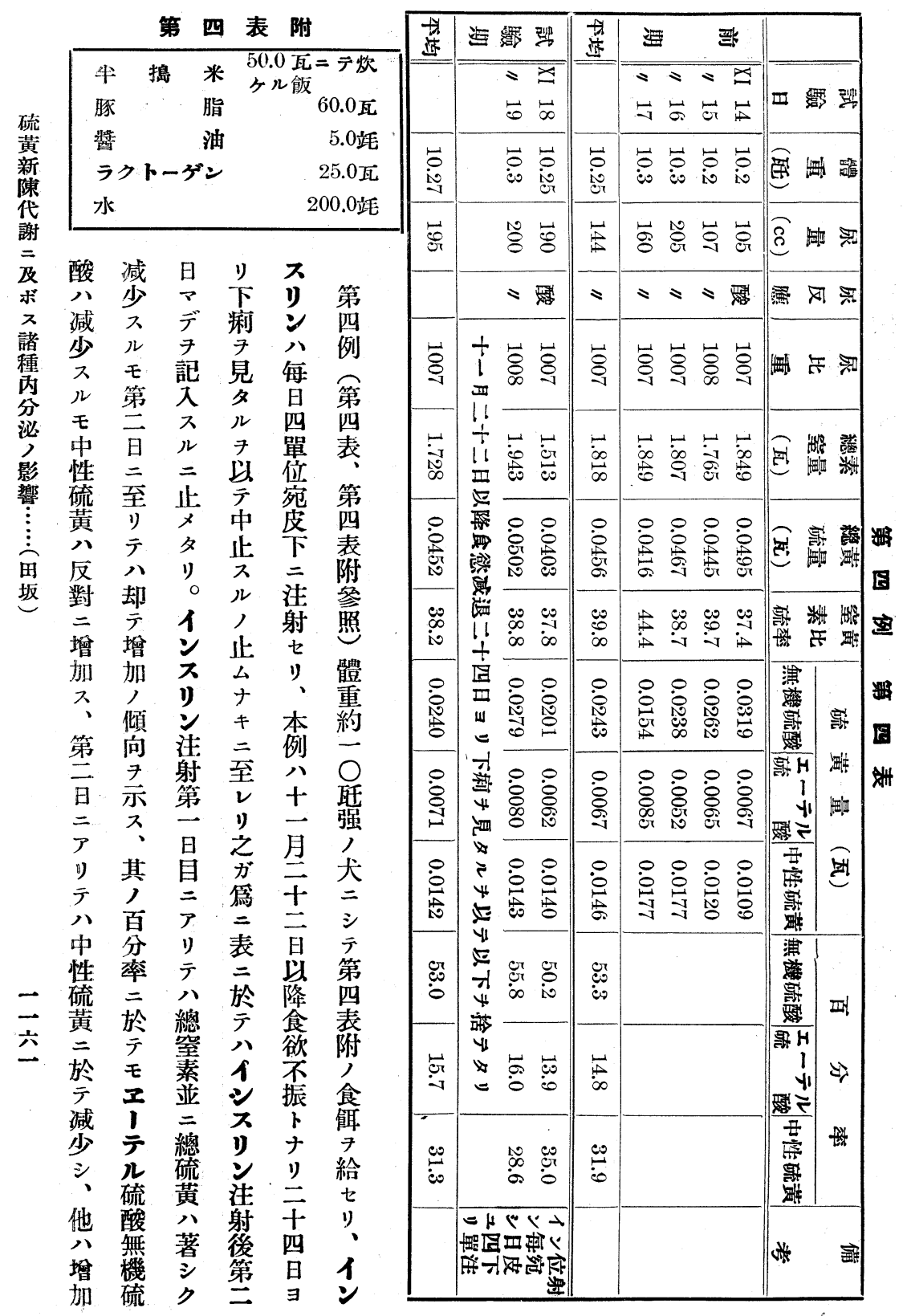




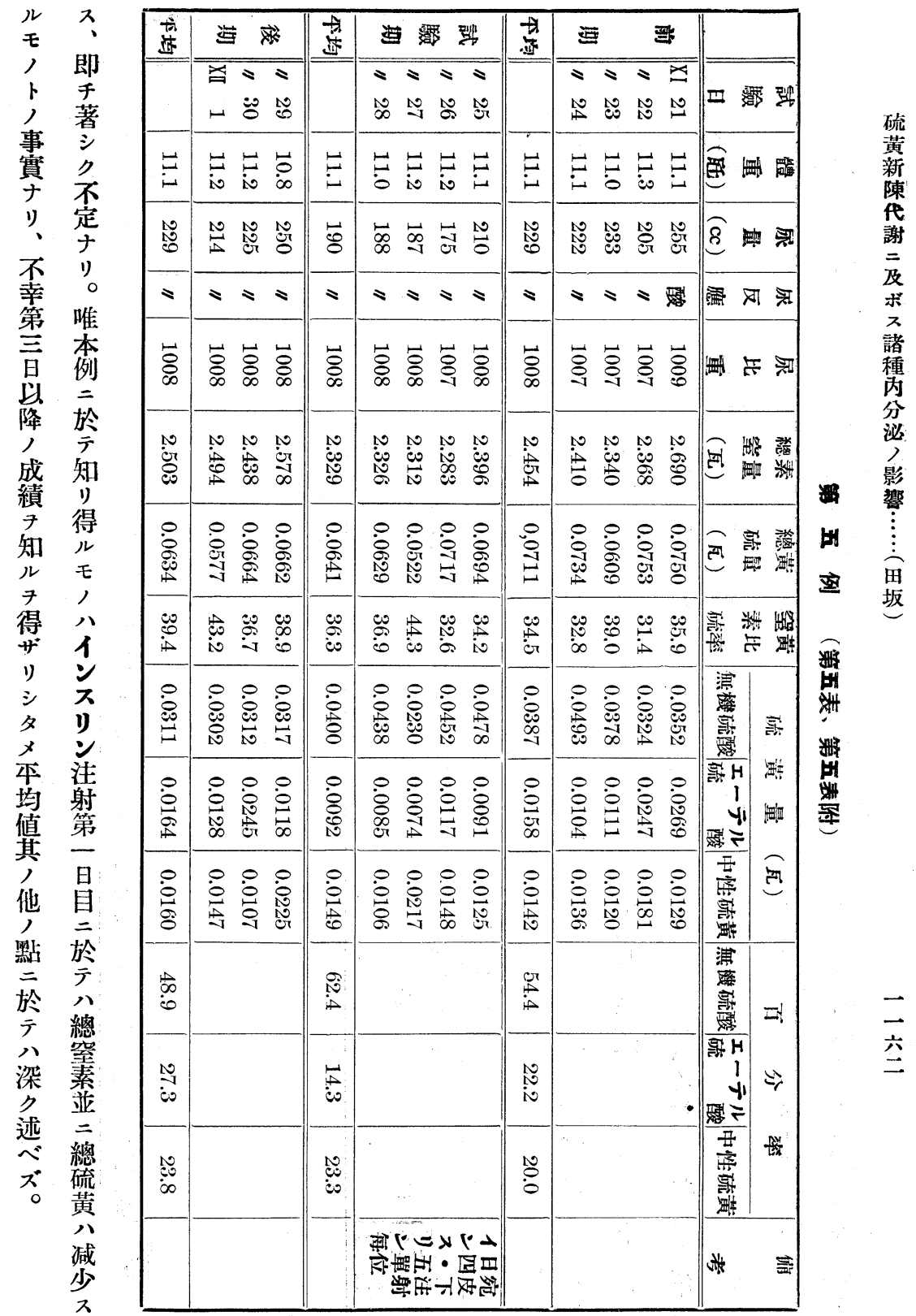




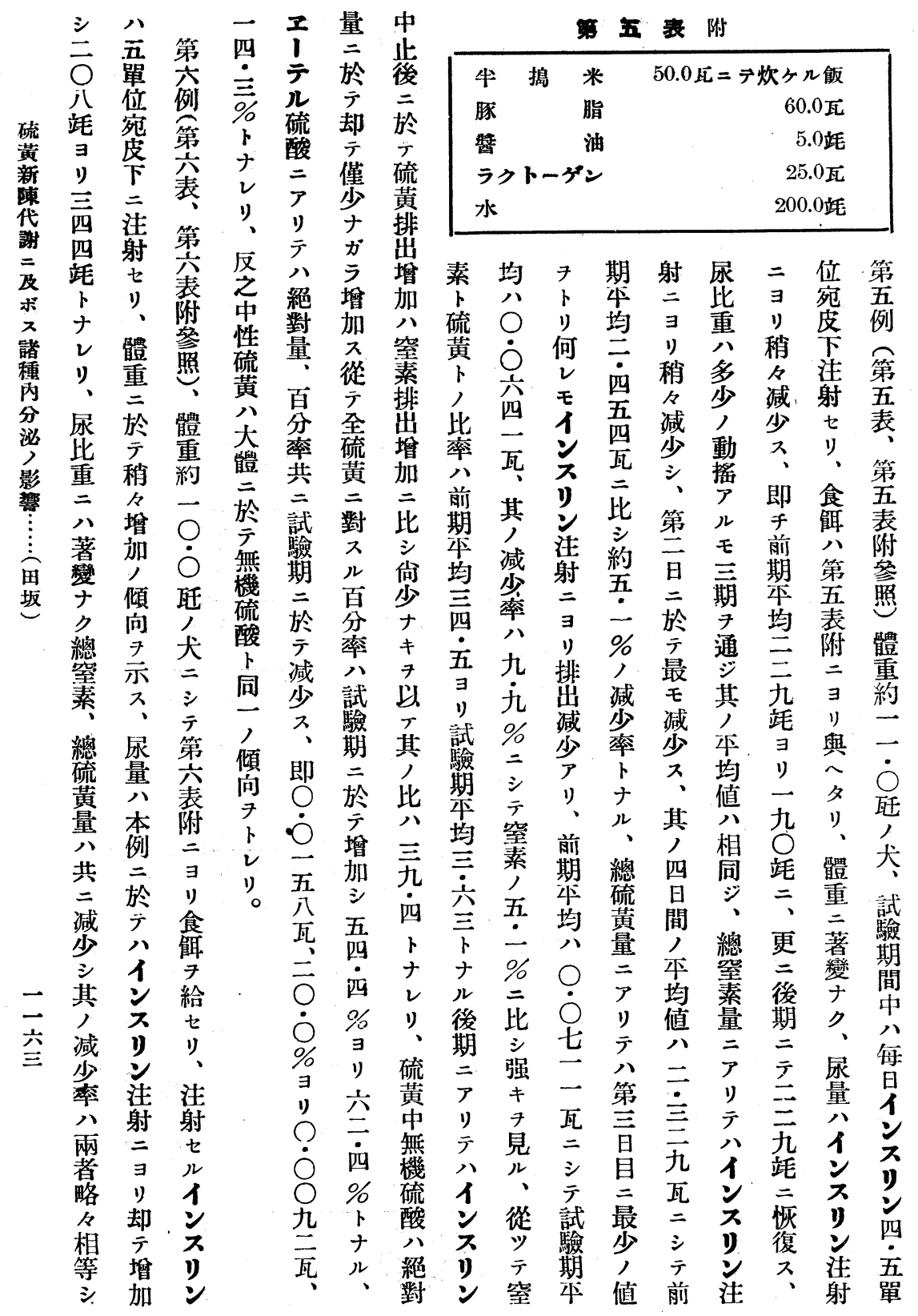




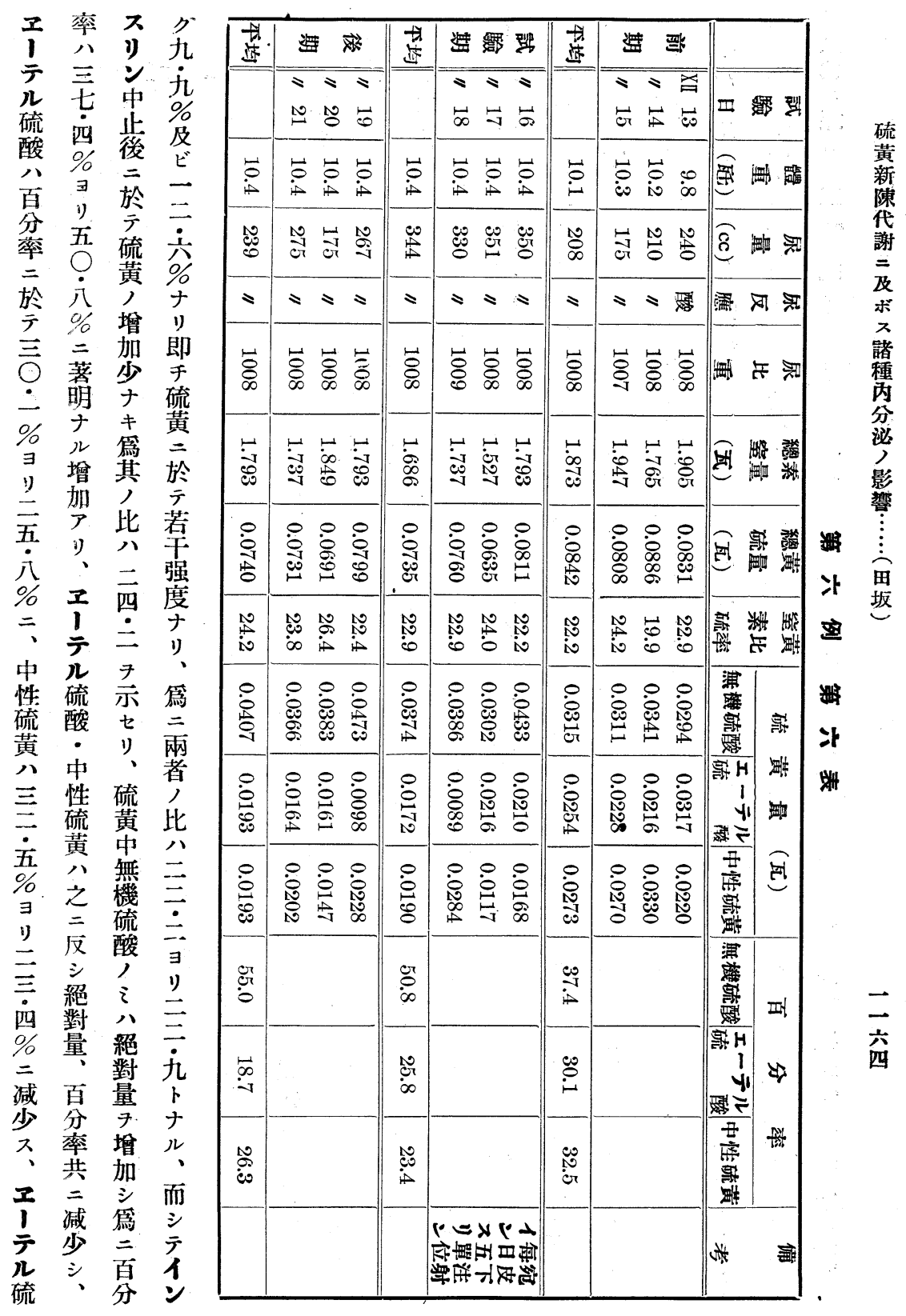




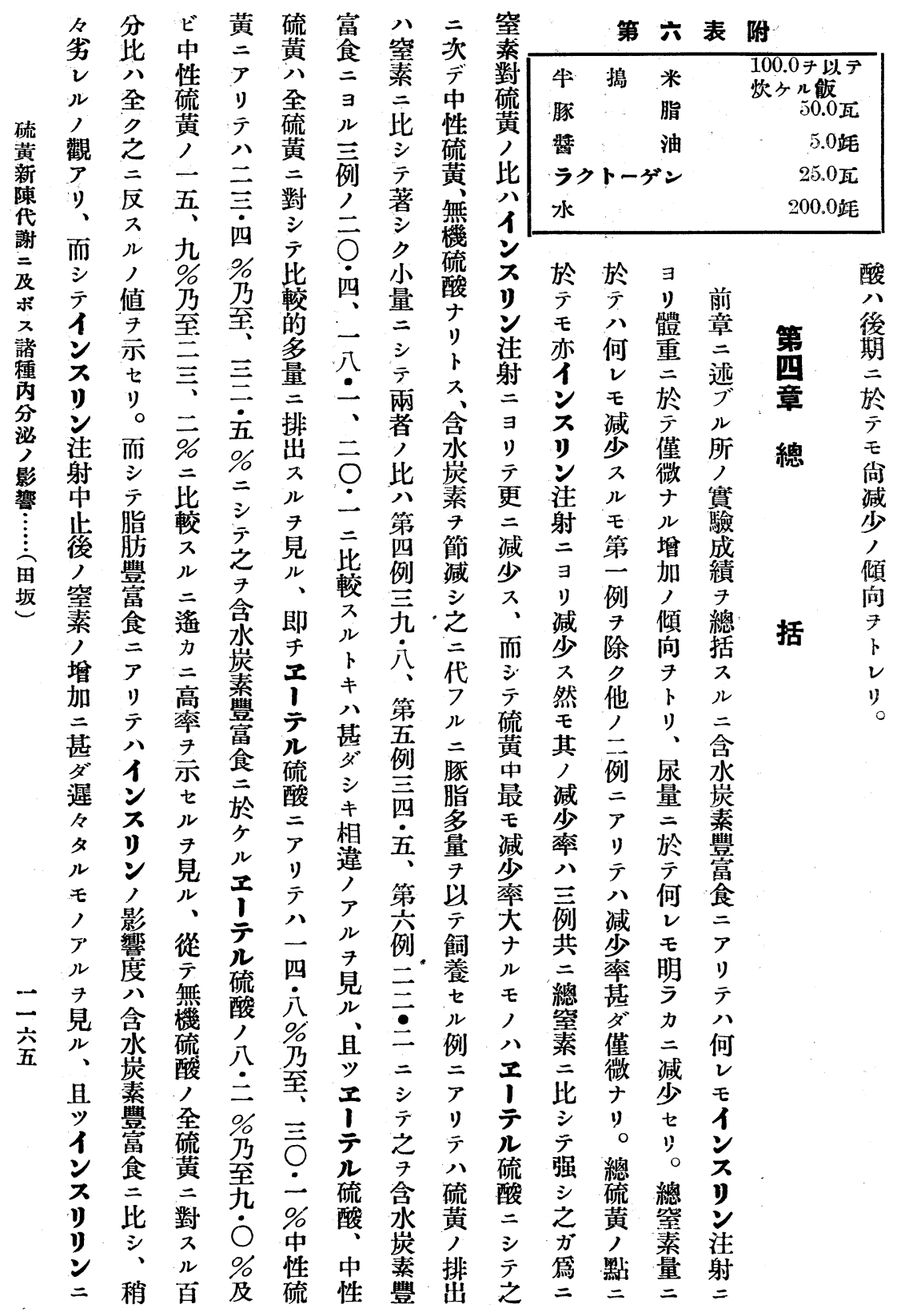




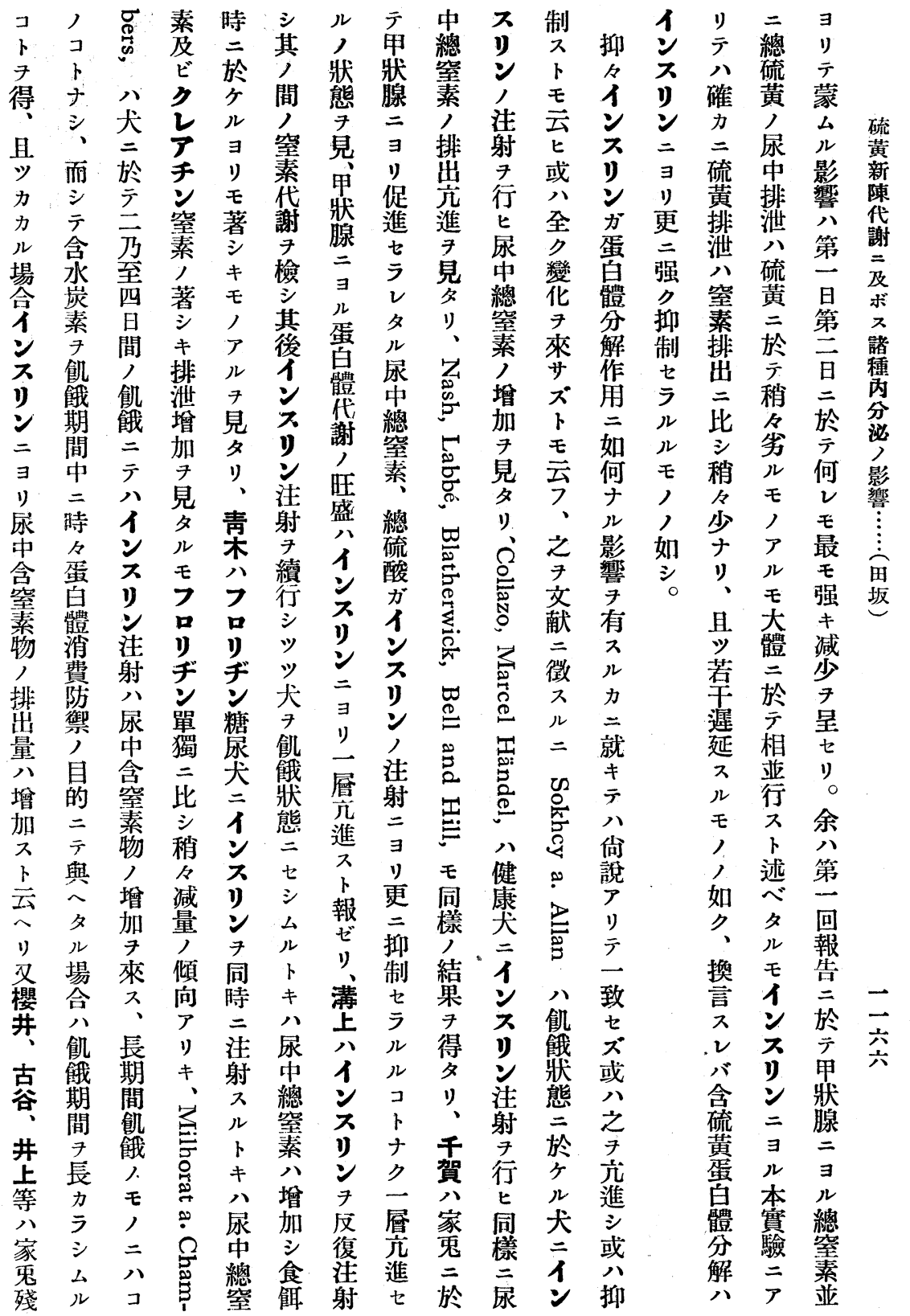




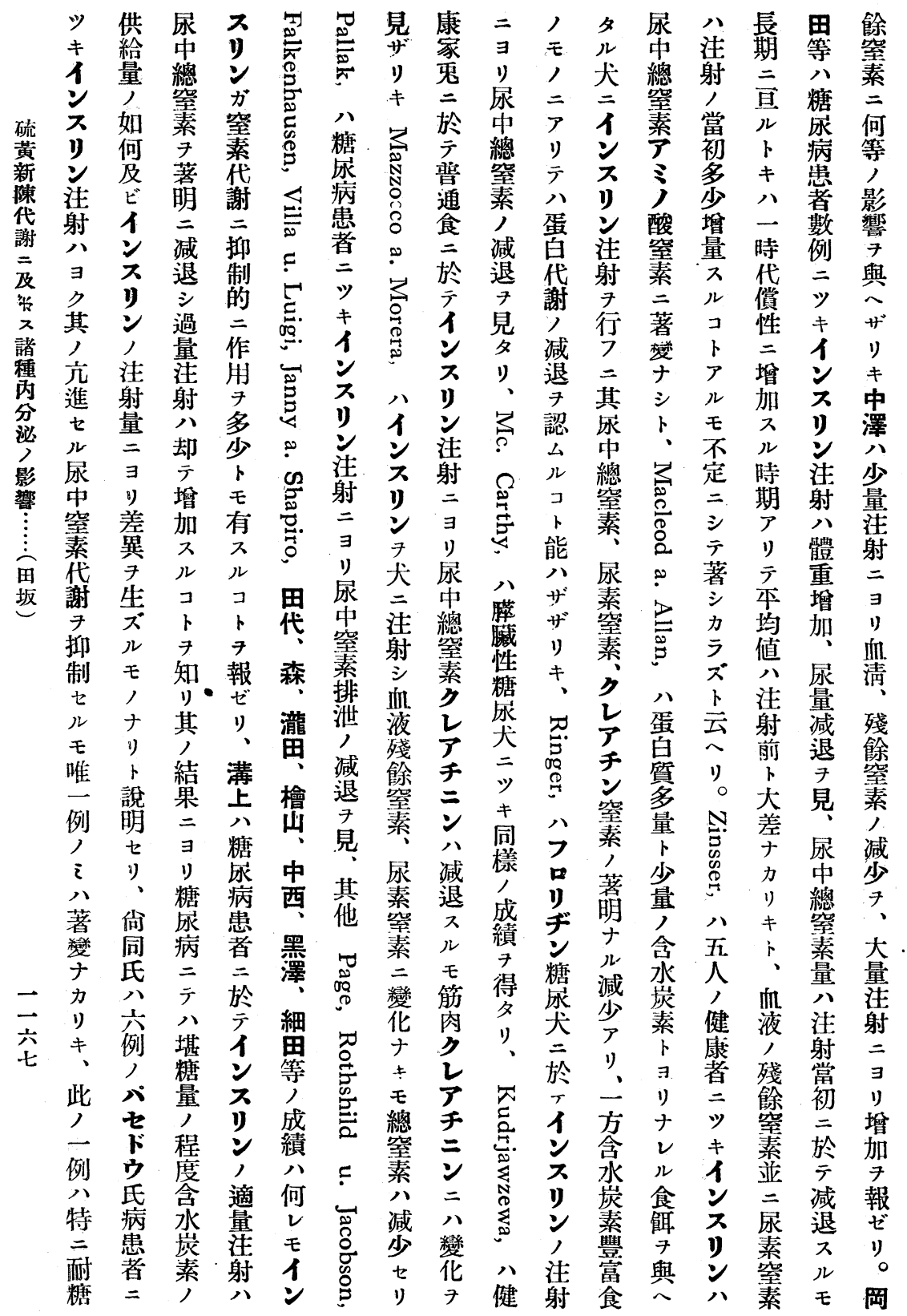




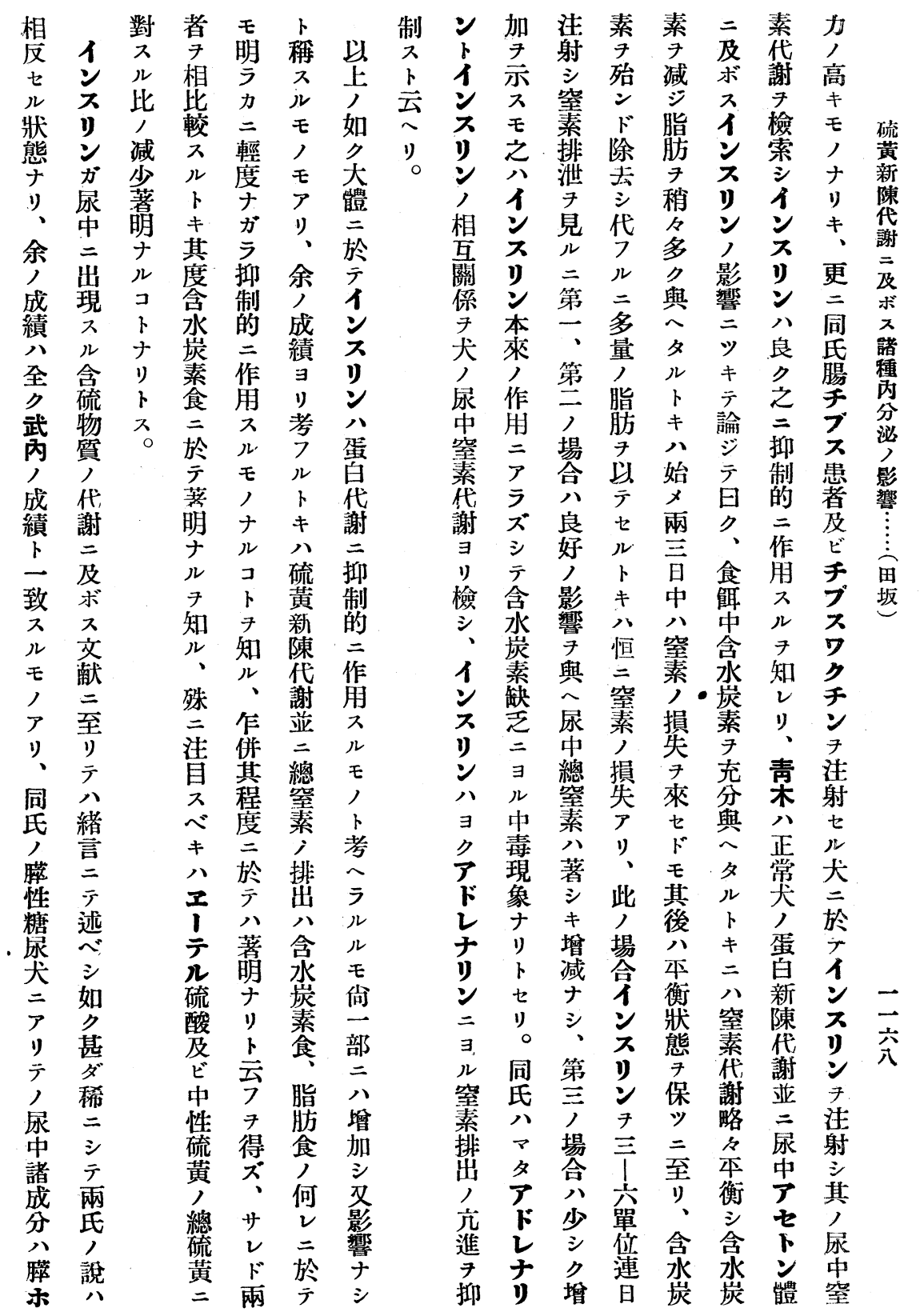




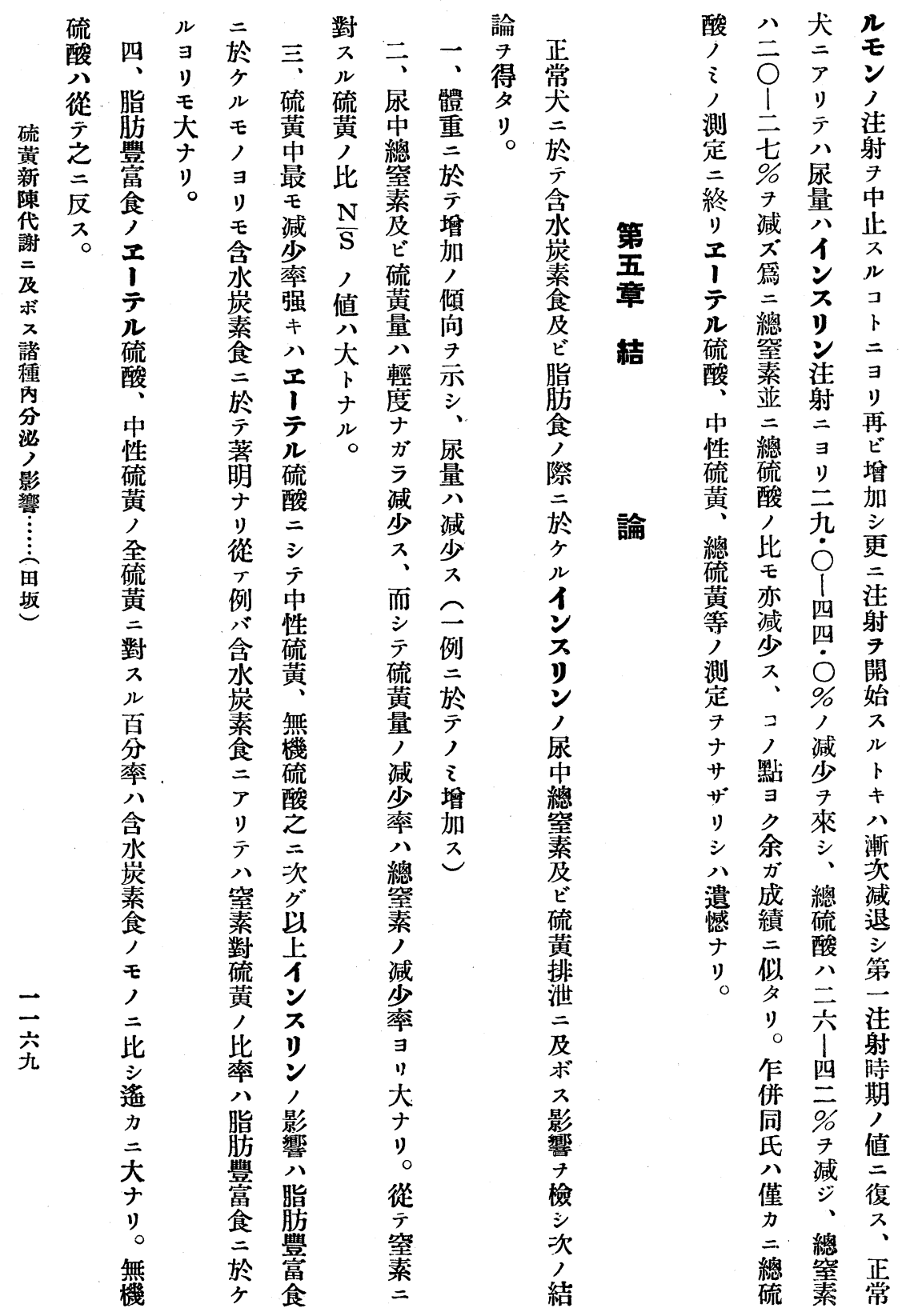




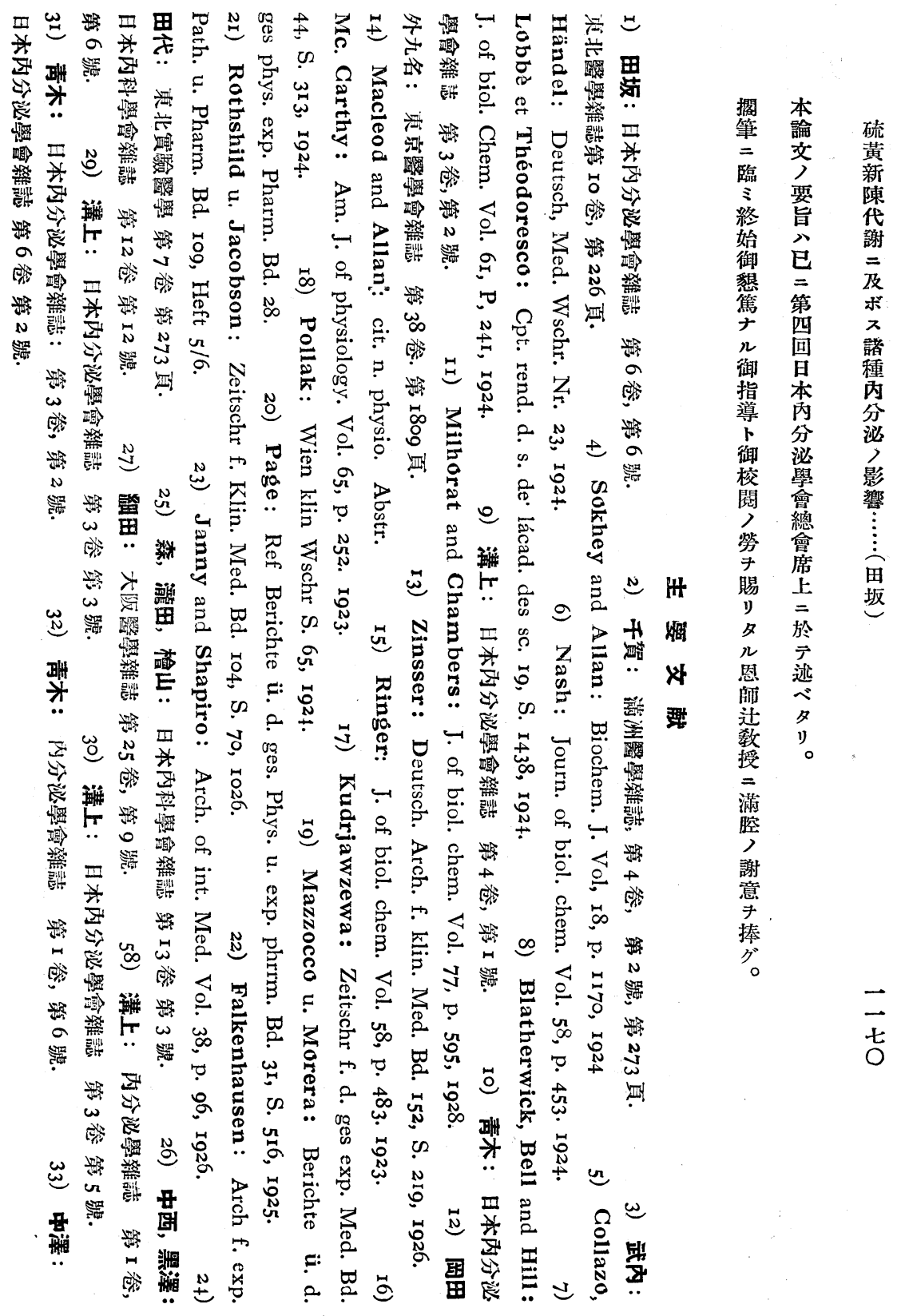




\section{FOLIA ENDOCRINOLOGICA JAPONICA}

\begin{tabular}{llc}
\hline \hline Band VI & Dezember & Heft 9 \\
\hline
\end{tabular}

\section{Ueber den Einfluss der endokrinen Drüsen auf den Schwefelstoffwechsel im Harn des Hundes. \\ II Mitteilung. Ueber den Einfluss des Insulins.}

\section{Von}

Dr. S. Tasaka.

(Aus der I med. Klinik der Kaiserl. Universitaet zu Kyoto, Japan. Direktor: Prof. Dr. K. Tsuji.)

In einer früheren Mitteilung hat der Verfasser bereits den Einfluss der Schilddrüse auf den Schwefelstoffwechsel festgestellt. In dieser Mitteilung hat er den Einfluss des Insulins auf die Schwefelausscheidung im Harn untersucht. $\mathrm{Zu}$ diesem Zweck wurden drei mit einer bestimmten kohlenhydratreichen Nahrung gefütterte gesunde erwachsene Hündinnen und drei mit einer bestimmten fettreichen Nahrung gefütterte gesunde erwachsene Hündinnen gebraucht. Der Gesamtstickstoff wurde nach Kjeldahl, der Gesamtschwefel, die anorganische Schwefelsäure und die Aetherschwefelsäure gravimetrisch bestimmt. Die, Resultate waren die folgenden :-

I) Das Körpergewicht neigt bei den dauernd mit Insulin subcutan injizierten Tieren zur Zunahme und die Harnmenge zur 
Verminderung.

2) Die Gesamt-N- und die Gesamt-S-ausscheidung im Harn war bei allen Fällen leichtgradig vermindert und die letztere etwas stärker als die erstere, wodurch der Quotient N/S Zunahme zeigte.

3) Die Aetherschwefelsäure war am deutlichsten vermindert, nächststark der neutrale Schwefel und drittens die anorganische Schwefelsäure.

4) Der Einfluss des Insulins war bei der mit Kohlenhydrat reich genährten Gruppe stärker als bei der mit Fett reich genährten. Daher war zum Beispiel der Wert des Quotienten $\mathrm{N} / \mathrm{S}$ bei der ersteren Gruppe grösser als bei der letzteren.

5) Das prozentuelle Verhältnis der Aetherschwefelsäure und des neutralen Schwefels zum Gesamtschwefel war bei der mit Fett reich genährten Gruppe weit grösser als bei der mit Kohlenhydrat reich genährten.

(Autoreferat)

\title{
Ueber den Einfluss der endokrinen Drüsen auf den Schwefelstoffwechsel im Harn des Hundes. III Mitteilung. Ueber den Einfluss der Nebennierenrinde.
}

\author{
Von \\ Dr. S. Tasaka.
}

(Aus der I med. Klinik der Kaiserl. Universitaet zu Kyoto, Japan.

Direktor : Prof. Dr. K. Tsuji.)

Der Verfasser hat bei 3 mit bestimmter Nahrung gefütterten, gesunden, erwachsenen Hündinnen den Einfluss des per os gegebenen getrockneten Nebennierenrindenpulver auf die Gesamt$\mathrm{N}$ - und die Schwefelausscheidung im Harn verfolgt und ist dabei zu den folgenden Resultaten gekommen. 